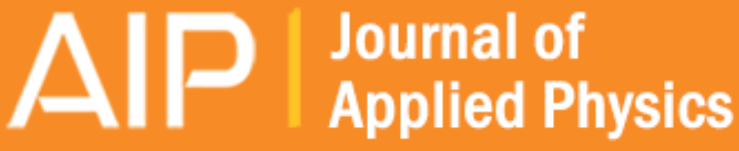

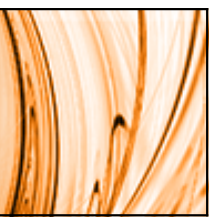

Langmuir probe measurements and mass spectrometry of plasma plumes generated by laser ablation of $\mathrm{La0.4 \textrm {Ca } 0 . 6 \mathrm { MnO } 3}$

Jikun Chen, James G. Lunney, Thomas Lippert, Alejandro Ojeda-G-P, Dieter Stender, Christof W. Schneider, and Alexander Wokaun

Citation: Journal of Applied Physics 116, 073303 (2014); doi: 10.1063/1.4893479

View online: http://dx.doi.org/10.1063/1.4893479

View Table of Contents: http://scitation.aip.org/content/aip/journal/jap/116/7?ver=pdfcov

Published by the AIP Publishing

\section{Articles you may be interested in}

A Langmuir probe diagnostic for time-of-flight measurements of transient plasmas produced by high-energy laser ablationa)

Rev. Sci. Instrum. 83, 10D725 (2012); 10.1063/1.4739312

Langmuir probe characterization of laser ablation plasmas

J. Appl. Phys. 105, 033306 (2009); 10.1063/1.3056131

Comparison of the ablation plumes arising from ArF laser ablation of graphite, silicon, copper, and aluminum in vacuum

J. Appl. Phys. 94, 2203 (2003); 10.1063/1.1592294

The Langmuir probe as a diagnostic of the electron component within low temperature laser ablated plasma plumes

Rev. Sci. Instrum. 70, 1801 (1999); 10.1063/1.1149672

Langmuir probe measurements of plasma parameters in the late stages of a laser ablated plume J. Appl. Phys. 81, 2131 (1997); 10.1063/1.364265

\section{SHIMADZU Powerful, Multi-functional UV-Vis-NIR and Excellence in Science FTIR Spectrophotometers}

Providing the utmost in sensitivity, accuracy and resolution for applications in materials characterization and nano research

- Photovoltaics - Ceramics

- Polymers - DNA film structures

- Thin films - Coatings

- Paints - Packaging materials
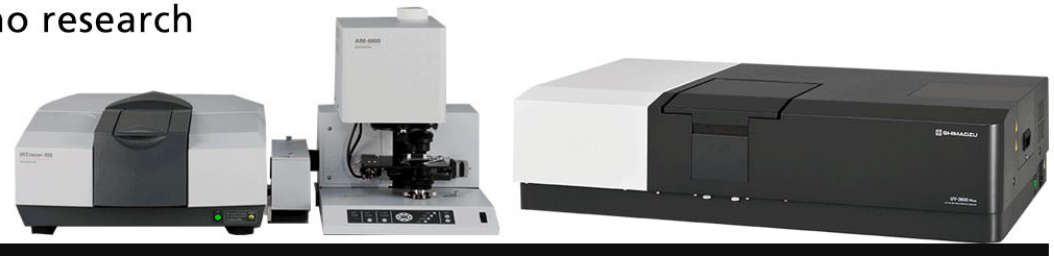


\title{
Langmuir probe measurements and mass spectrometry of plasma plumes generated by laser ablation of $\mathrm{La}_{0.4} \mathrm{Ca}_{0.6} \mathrm{MnO}_{3}$
}

\author{
Jikun Chen (陈吉陈), ${ }^{1}$ James G. Lunney, ${ }^{2}$ Thomas Lippert, ${ }^{1,}$ a) Alejandro Ojeda-G-P, ${ }^{1}$ \\ Dieter Stender, ${ }^{1}$ Christof W. Schneider, ${ }^{1}$ and Alexander Wokaun ${ }^{1}$ \\ ${ }^{1}$ Department of General Energy Research, Paul Scherrer Institut, 5232 Villigen PSI, Switzerland \\ ${ }^{2}$ School of Physics and CRANN, Trinity College, Dublin 2, Ireland
}

(Received 20 May 2014; accepted 25 July 2014; published online 21 August 2014)

\begin{abstract}
The plasma formed in vacuum by UV nanosecond laser ablation of $\mathrm{La}_{0.4} \mathrm{Ca}_{0.6} \mathrm{MnO}_{3}$ in the fluence range of 0.8 to $1.9 \mathrm{~J} \mathrm{~cm}^{-2}$ using both Langmuir probe analysis and energy-resolved mass spectrometry has been studied. Mass spectrometry shows that the main positive ion species are $\mathrm{Ca}^{+}, \mathrm{Mn}^{+}$, $\mathrm{La}^{+}$, and $\mathrm{LaO}^{+}$. The $\mathrm{Ca}^{+}$and $\mathrm{Mn}^{+}$energy distributions are quite broad and lie in the $0-100 \mathrm{eV}$ region, with the average energies increasing with laser fluence. In contrast, the $\mathrm{La}^{+}$and $\mathrm{LaO}^{+}$distributions are strongly peaked around $10 \mathrm{eV}$. The net time-of-arrival signal derived from the measured positive ion energy distributions is broadly consistent with the positive ion signal measured by the Langmuir probe. We also detected a significant number of $\mathrm{O}^{-}$ions with energies in the range of 0 to $10 \mathrm{eV}$. The Langmuir probe was also used to measure the temporal variation of the electron density and temperature at $6 \mathrm{~cm}$ from the ablation target. In the period when $\mathrm{O}^{-}$ions are found at this position, the plasma conditions are consistent with those required for significant negative oxygen ion formation, as revealed by studies on radio frequency excited oxygen plasma. (C) 2014 AIP Publishing LLC. [http://dx.doi.org/10.1063/1.4893479]
\end{abstract}

\section{INTRODUCTION}

Pulsed laser deposition (PLD) is a well suited deposition technique to prepare thin films, in particular, oxides with a complex stoichiometry, by removing material from a bulk target using a pulsed laser beam. ${ }^{1-3}$ The evaporated plasma plume contains ionized atoms and molecules, neutrals and electrons, and the kinetics of the plasma plume will have a direct influence on the structural and physical properties of a deposited film. To better understand these plasma properties, a range of plasma analytical techniques such as Langmuir probe ${ }^{4-10}$ plasma imaging, ${ }^{11-14}$ emission spectroscopy, ${ }^{15-20}$ and mass spectrometry ${ }^{21-26}$ have been used also in a number of combinations to cover different aspects and properties of plasma species. ${ }^{27,28}$ For example, Geohegan and Puretzky investigated the laser ablation plume thermalization dynamics in background gases thereby combining optical absorption and emission spectroscopy, imaging and ion probe analysis. ${ }^{27}$ Amoruso et al. characterized the laser induced $\mathrm{LaMnO}_{3}$ plasma by ion probe and optical emission spectroscopy and developed the distance-related pressure dependencies for the different expansion regimes. ${ }^{28}$

Langmuir probe analysis and mass spectroscopy have the advantage that charged species can be detected irrespective of their excited state, whereas neutral species are more difficult to quantify, or cannot be readily measured. Excited state neutral and ionized species are detected in emission spectroscopy and plasma imaging, but a quantitative analysis is difficult to achieve. Langmuir probe measurement is a relatively simple and direct plasma diagnostic technique. ${ }^{4-10} \mathrm{~A}$ small metal probe with variable bias voltage is placed in the

\footnotetext{
${ }^{\text {a) }}$ Author to whom correspondence should be addressed. Electronic mail: Thomas.lippert@psi.ch. Fax: +41563102688.
}

flowing ablation plasma, and, depending on the polarity of the bias, an electron or positive ion current is collected as the plasma flows past the probe leading to the time-of-arrival (TOA) distribution. The TOA distributions usually show the presence of a smooth current signal for both elemental and multi-component target. ${ }^{29}$ For a sufficiently negative bias, electrons are rejected at the probe, and the TOA distribution can be used to find the ion velocity and kinetic energy distributions associated with the plasma flow. The voltage bias on a Langmuir probe can also be varied to measure the $I V$ characteristic, and thence determine the electron temperature $\left(T_{e}\right){ }^{4}$ Langmuir probe analysis is most suitable when one ionic species is dominant, as is the case for ablation of an elemental metal target. ${ }^{5}$ However, for many PLD applications compound targets with a complex chemical composition are used and different ionic species are present in the plasma, all of which contribute to the ion current signal in a Langmuir probe measurement. Mass spectroscopy may be used to distinguish different ion masses and charge. In previous studies, both quadrupole $\mathrm{e}^{21,25}$ and time-of-fight mass spectrometers $^{22-24}$ have been used to determine the ionic composition of the plume. Since Langmuir probe analysis and mass spectrometry have different advantages and limitations, it is of interest to explore what can be learned by using a combination of the two techniques, and to determine the extent to which the two measurements can be reconciled. Combining mass spectrometry with Langmuir probe (or ion collector) measurements have been reported previously. ${ }^{30-34}$ This combination has been used mostly to extend the kinetic energy range for energy resolved mass spectrometry in order to measure the shorter time of arrival of fast moving ionic plasma species.

In this paper, we report how Langmuir probe analysis and energy resolved mass spectrometry are used to 
investigate the plasma properties of $\mathrm{La}_{0.4} \mathrm{Ca}_{0.6} \mathrm{MnO}_{3}$ (LCMO) at various laser fluences with the aim of showing how results of these two techniques can be compared directly. A Langmuir probe measures the TOA distribution of positive ionic species, the electron temperature, and density. The quadrupole mass spectrometer combined with an electrostatic kinetic energy $\left(E_{k}\right)$ analyzer measures the $E_{k}$ distributions of ionic species. From the experimentally determined $E_{k}$ distributions, a TOA can be calculated for each of the ionic species. Summing up all TOAs yields an overall TOA distribution, which can be compared to the measured TOA distribution from the Langmuir probe. The comparison of these TOA distributions allows to distinguish the contribution from different species to the total detected TOA distribution as determined from mass spectrometry and hence will improve the understanding of Langmuir probe measurements when dealing with the characterization of a laser generated plasma from multi-elemental targets.

\section{EXPERIMENTAL METHODS}

The Langmuir probe and mass spectrometry plasma analysis experiments were carried out in a ultra-high vacuum chamber at $\sim 10^{-8}$ mbar as illustrated in Figs. 1(a) and 1(b). The plasma was generated using a $\mathrm{XeCl}$ excimer laser beam $(\lambda=308 \mathrm{~nm}, \tau=25-30 \mathrm{~ns}$, freq. $=5 \mathrm{~Hz})$ imaged onto a rotating ceramic disc target of LCMO placed at the centre of the chamber. The angle of incidence was $45^{\circ}$ and fluence values of $0.8,1.3$, and $1.9 \mathrm{~J} \mathrm{~cm}^{-2}$ were used. The target could be rotated to face either the Langmuir probe or the mass spectrometer, as shown in Figs. 1(a) and 1(b). The laser signal is measured by a photodiode, which acts as the reference of the zero time for the Langmuir probe measurement.

A rod-shaped Langmuir probe of $3 \mathrm{~mm}$ diameter and $36 \mathrm{~mm}$ length was placed in front of the target at a distance which can be varied from 6 to $14 \mathrm{~cm}$ as measured from the tip of the probe. The probe lies parallel to the normal of the target surface and points towards the laser ablation spot; hence, the cylindrical surface of the probe is parallel to the plasma flow (Fig. 1(c)). In this geometry, the probe signal is nearly proportional to the ion density and $V^{0.5}, 7$ unlike a flat probe lying perpendicular to the plasma flow where the signal is proportional to the ion flux (density $\mathrm{x}$ velocity). Following the analysis in Ref. 7, it can be shown that for the plasma conditions at $6 \mathrm{~cm}$ from the target the ion signal is mainly collected at $\sim 6 \mathrm{~mm}$ near the tip of the probe, arising from the formation of a matrix sheath in that region. Further along the probe a Child-Langmuir sheath is formed and a smaller current density is extracted from the plasma. The matrix sheath thickness varies as $V^{0.5}$ which corresponds to a thickness of $\sim 2 \mathrm{~mm}$ if the probe is biased at $10 \mathrm{~V}$, a value larger than the radius of the probe. The ion signal is, therefore, expected to vary approximately as sheath thickness squared, i.e., as V. Thus, we would not expect our signal to saturate. However, the flat end of the probe could still contribute which may happen at early arrival times where the plasma velocity is higher. The current drawn by the probe was determined by measuring the voltage across a load resistor, which had values of $10 \Omega$ or $50 \Omega$, depending on the signal to be measured as illustrated in Fig. 1(d). The probe signals were averaged over 40 laser shots.

The mass spectrometry measurements were conducted using a high-transmission $45^{\circ}$ sector field ion energy analyzer combined with an electrostatic quadrupole mass spectrometer (EQP-QMS, Hiden) and an entry orifice of $0.06 \mathrm{~mm}$ to enable operation at elevated pressures and high plasma densities. ${ }^{31,35}$ The incoming ions are first filtered by the field ion analyzer, which allows the ionic species with a defined kinetic energy to pass the $45^{\circ}$ sector analyser. Afterwards, the passed ions are further filtered by a quadrupole mass selector, which allows the ionic species with a defined massto-charge ratio to pass. By tuning the pass energy of the kinetic energy analyzer and measure the signal from a specific ionic species with defined mass to charge ratio, the ion kinetic energy distribution $d N / d E_{k}$ of each ion species is measured. The pressure in the mass spectrometer system was (a)

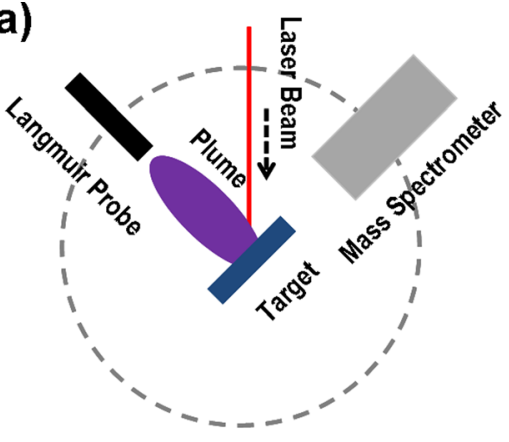

Plasma analysis using the Langmuir probe (b)

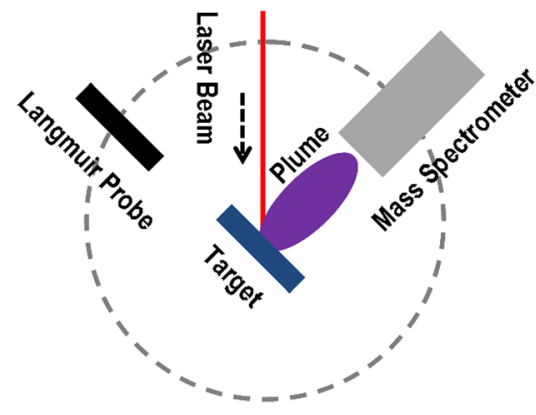

Plasma analysis using the mass spectrometer (c)

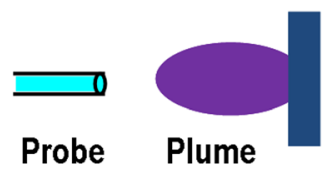

(d)

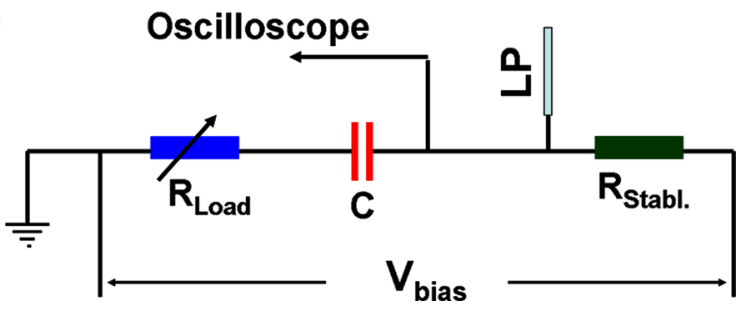

FIG. 1. Illustration of experimental configurations used for (a) mass spectrometry and (b) Langmuir analysis. (c) Illustration of the orientation of the Langmuir probe with respect to the plasma plume. (d) Illustration of the Langmuir probe bias circuit. The capacitor (C) is $470 \mathrm{nF}$, while the charging resistance $\mathrm{R}_{\text {charg. }} \approx 472 \mathrm{k} \Omega$. 

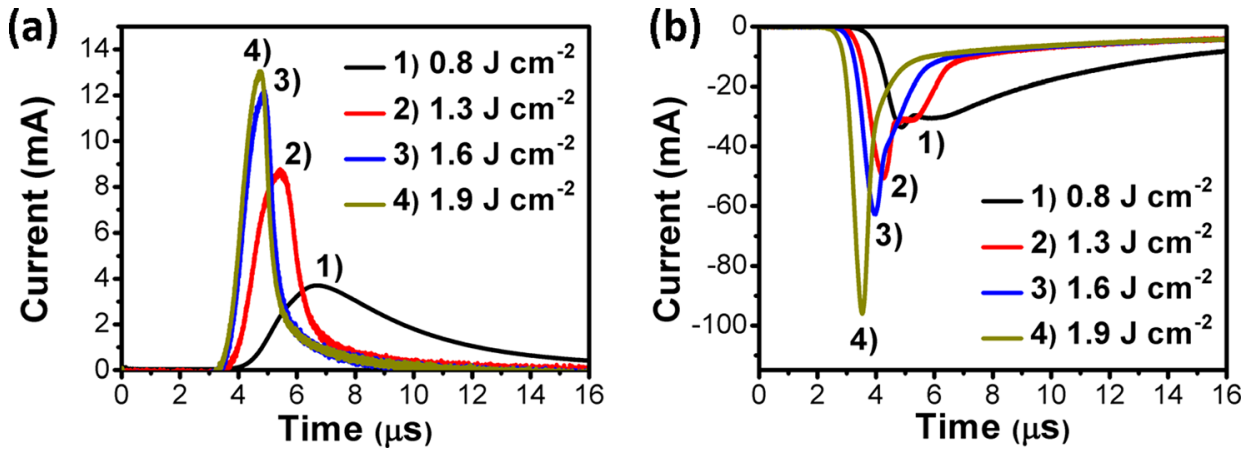

FIG. 2. Langmuir probe signal recorded at $6 \mathrm{~cm}$ for the target for laser ablation of LMCO at several values of laser fluence: (a) Positive ion signal recorded at $-10 \mathrm{~V}$ bias, (b) electron signal at $10 \mathrm{~V}$ bias. maintained at $10^{-8}$ mbar by differential pumping. The distance from the target surface to the entrance aperture on the spectrometer was $6 \mathrm{~cm}$ for all measurements. The voltages on the extractor and the electrostatic lenses at the entrance of the detector were tuned to obtain the optimum detection efficiency for each of the ions investigated.

\section{RESULTS AND DISCUSSION}

\section{A. Langmuir probe measurements}

Figure 2 shows the TOA distributions recorded for probe bias voltages of $-10 \mathrm{~V}$ (a) and $10 \mathrm{~V}$ (b) with the Langmuir probe at $6 \mathrm{~cm}$ for various values of laser fluence. As expected, with a negative bias, the electron flow to the probe is suppressed and positive ions extracted from the plasma give rise to a positive current to the probe. With a positive bias, electrons can reach the probe surface, giving rise to a negative current, the value depending on the bias voltage and the TOA. As has been observed before, the magnitude of the detected negative current signals greatly exceeds the positive current signals, due to the much lower electron mass [4-7]. With decreasing laser fluence, the amplitudes of the positive and negative current signals decrease, while their arrival times are delayed, indicating a decrease in the amount and expansion velocity of the laser ablation plume. It can be noted that for laser fluences larger than $1.6 \mathrm{~J} \mathrm{~cm} \mathrm{~cm}^{-2}$, the negative and positive TOA distributions show a single sharp peak, while for fluence values below $1.3 \mathrm{~J} \mathrm{~cm}^{-2}$ a double peak is observed for the negative TOA distributions. The origin of this double peak is not clear at present.

Laser fluence values of $0.8 \mathrm{~J} \mathrm{~cm}^{-2}$ and $1.9 \mathrm{~J} \mathrm{~cm}^{-2}$ were selected for more extensive Langmuir probe investigation. Fig. 3 shows the TOA distributions for several values of bias voltage for these two fluence values. For $0.8 \mathrm{~J} \mathrm{~cm}^{-2}$, the duration of the positive ion signal increases as the bias is increased for $-2 \mathrm{~V}$ to $-10 \mathrm{~V}$, but remains constant for higher bias voltage. For $0.8 \mathrm{~J} \mathrm{~cm} \mathrm{~cm}^{-2}$, a double peak is observed for positive bias above $3 \mathrm{~V}$; the relative amplitude of the second maximum grows with increasing bias, becoming larger than the first peak for bias greater than $10 \mathrm{~V}$. In contrast, at $1.9 \mathrm{~J}$ $\mathrm{cm}^{-2}$ the negative TOA distribution is single-peaked. Increasing the bias voltage up to $30 \mathrm{~V}$ leads to a pronounced growth of the current amplitude in the time interval of 5 to $20 \mu$ s after the laser pulse.

The expansion velocity of the plasma plume was determined by changing the target-probe distance, from 6 to $14 \mathrm{~cm}$ in $2 \mathrm{~cm}$ steps, and recording the positive ion signals for $10 \mathrm{~V}$ bias at each position. These signals are shown in Fig. 4. As the probe-target distance is increased, the current peaks move to later times, are reduced in amplitude, and are broadened. The broadening of the TOA distributions with increasing target-probe distance is as expected for the inertial
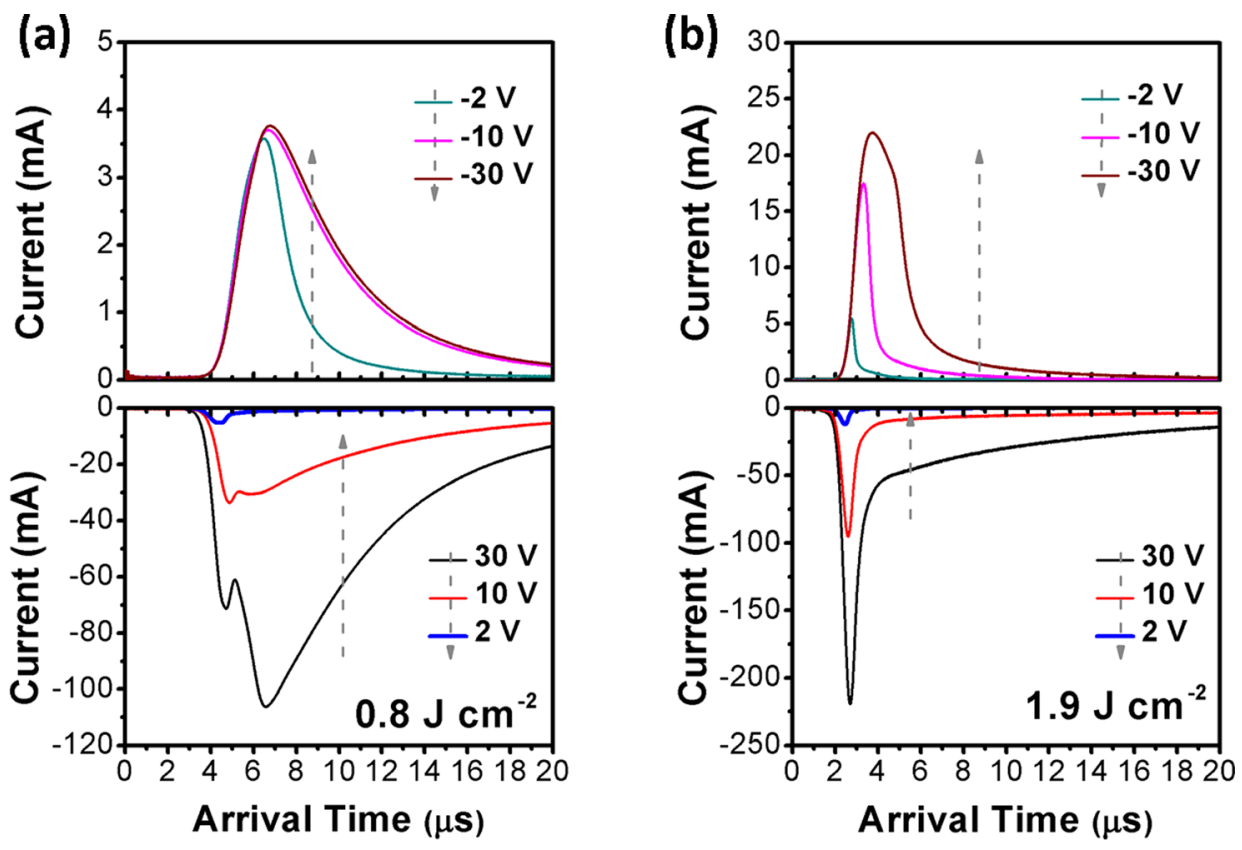

FIG. 3. TOA signals recorded at $6 \mathrm{~cm}$ from the target for various values of probe bias in the range of $30 \mathrm{~V}$ to $-30 \mathrm{~V}$ at fluence values of: (a) $0.8 \mathrm{~J}$ $\mathrm{cm}^{-2}$ and (b) $1.9 \mathrm{~J} \mathrm{~cm}^{-2}$. 


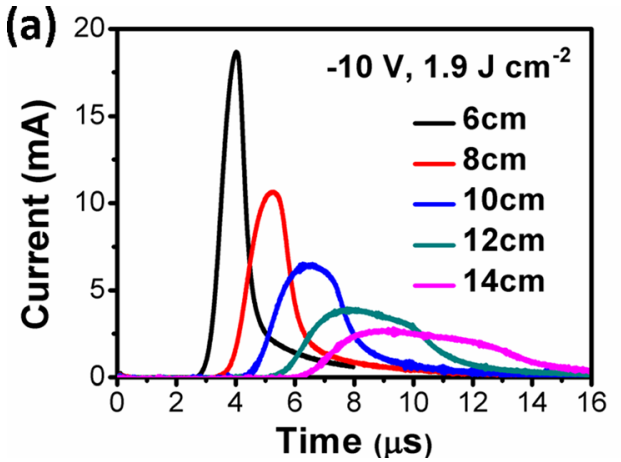

phase of plume expansion with the usual distribution of the ion velocity. For each fluence value, the plasma velocities were found by making a linear fit to a plot of the distance vs TOA of the signal peak. The values obtained were $1 \times 10^{4} \mathrm{~m}$ $\mathrm{s}^{-1}$ for $0.8 \mathrm{~J} \mathrm{~cm}^{-2}$ and $1.5 \times 10^{4} \mathrm{~m} \mathrm{~s}^{-1}$ for $1.9 \mathrm{~J} \mathrm{~cm}^{-2}$. Similar experiments were carried out to investigate the velocity of the negatively charged species with $1.2 \times 10^{4} \mathrm{~m} \mathrm{~s}^{-1}$ for $0.8 \mathrm{~J} \mathrm{~cm}^{-2}$ and $1.9 \times 10^{4} \mathrm{~m} \mathrm{~s}^{-1}$ for $1.9 \mathrm{~J} \mathrm{~cm}^{-2}$. The larger velocity measured for the negative current signal as compared for the positive signal is considered to be a

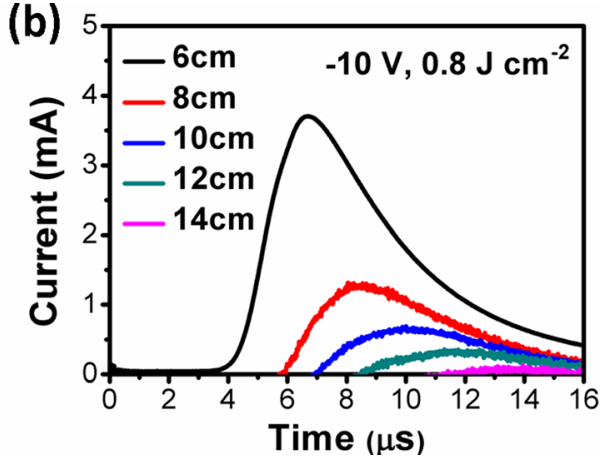

FIG. 4. Ion signals recorded at $-10 \mathrm{~V}$ bias and various distances from the target with laser fluences of: (a) $0.8 \mathrm{~J}$ $\mathrm{cm}^{-2}$ and (b) $1.9 \mathrm{~J} \mathrm{~cm}^{-2}$.
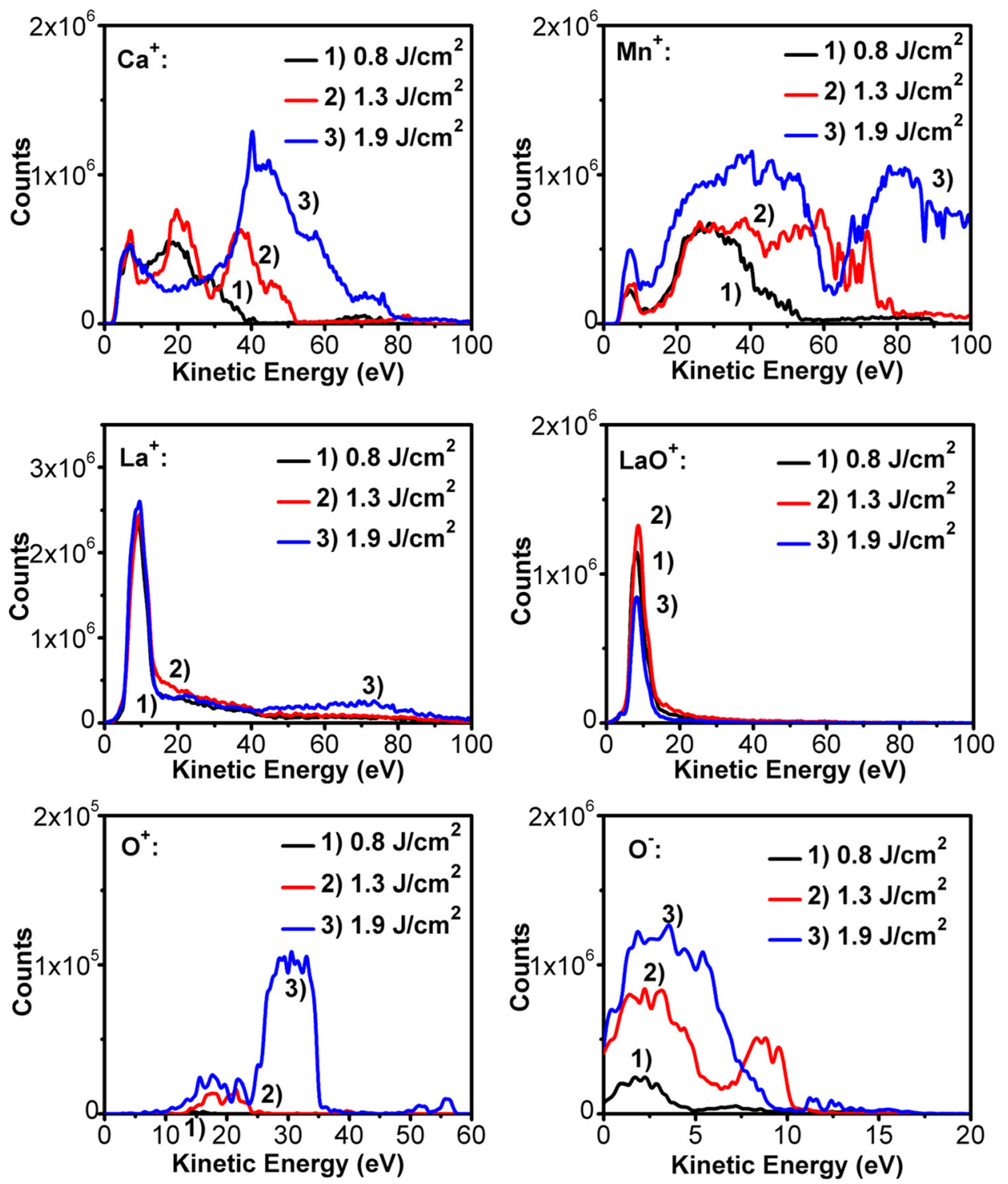

confirmation of an expected behavior. The Langmuir probe signal for positive bias is dominated by electrons since the thermal velocities of the lighter electrons are much higher than the flow velocities of any negative ions present in the plasma.

\section{B. Ion energy distribution}

Figure 5 shows the kinetic energy distributions, as measured with the mass spectrometer system, of the positive
FIG. 5. Mass spectrometer measurements of the kinetic energy distributions of the $\mathrm{Ca}^{+}, \mathrm{Mn}^{+}, \mathrm{La}^{+}, \mathrm{LaO}^{+}$, $\mathrm{O}^{+}$, and $\mathrm{LaO}^{+}$ions at $0.8 \mathrm{~J} \mathrm{~cm}^{-2}, 1.3 \mathrm{~J}$ $\mathrm{cm}^{-2}$, and $1.9 \mathrm{~J} \mathrm{~cm}^{-2}$. 

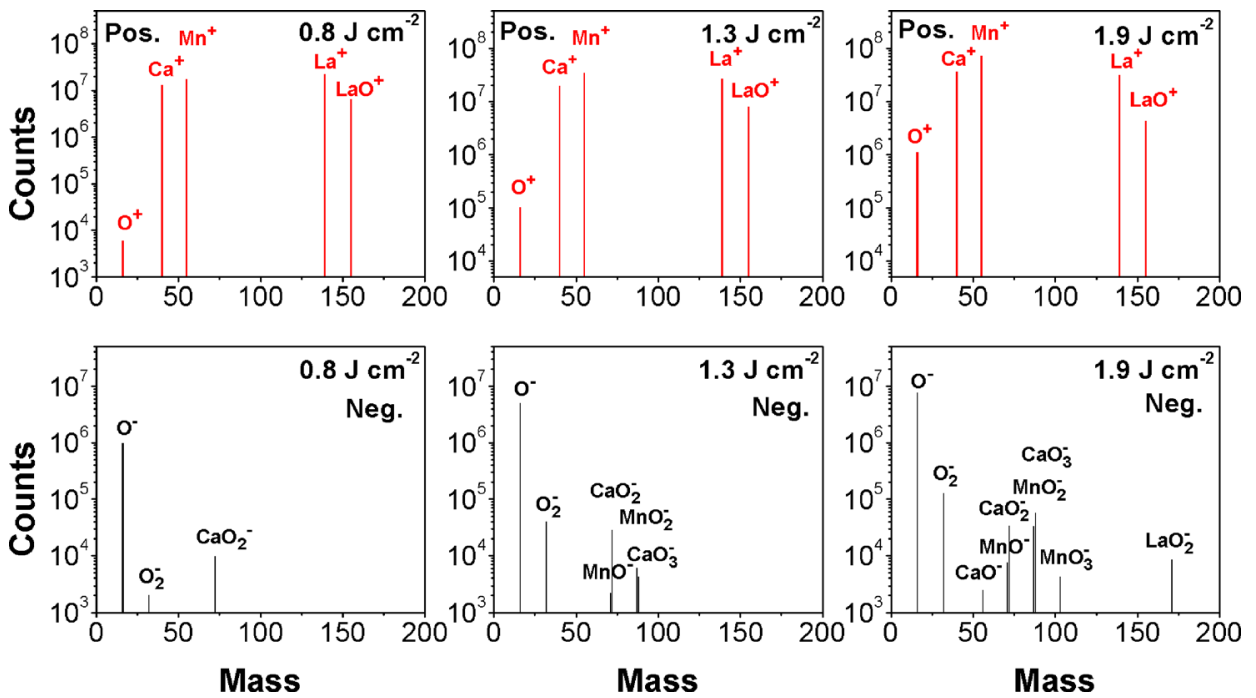

atomic ions $\mathrm{Ca}^{+}, \mathrm{Mn}^{+}$, and $\mathrm{La}^{+}$, the molecular ion $\mathrm{LaO}^{+}$ and the negative ion $\mathrm{O}^{-}$, which are the main ionic species detected in the plume. The energy distributions are shown for fluence values of $0.8,1.3$, and $1.9 \mathrm{~J} \mathrm{~cm}^{-2}$. By integrating these distributions over energy, the relative abundance of each species was determined; the results are shown in Fig. 6. This figure also shows the values for several other lowabundance negative ions.

While the energy spectra are quite complex, some particular features and fluence dependencies can be discerned. The energy distributions of $\mathrm{Ca}^{+}$and $\mathrm{Mn}^{+}$are relatively broad, and extend out to higher energies as the laser fluence is increased. In contrast, the heavier $\mathrm{La}^{+}$ion shows a strong peak around $10 \mathrm{eV}$, which does not change with fluence. There is a weak tail on the $\mathrm{La}^{+}$distribution, which extends to higher energy as the fluence is increased, reaching $\sim 100 \mathrm{eV}$ at $1.9 \mathrm{~J} \mathrm{~cm}^{-2} . \mathrm{LaO}^{+}$is the main metal-oxygen species detected, which may be attributed to its relatively high dissociation energy, estimated to be $\sim 8.9 \mathrm{eV} .{ }^{25}$ Its distribution also shows a strong peak around $10 \mathrm{eV}$ which decreases as the fluence is increased from 1.3 to $1.9 \mathrm{~J} \mathrm{~cm}^{-2}$, perhaps indicating the increasing influence of dissociation as more laser energy is coupled to the ablation plume. Both $\mathrm{O}^{+}$ and $\mathrm{O}^{-}$are clearly observed in the mass spectra, and the strength of both signals grows with laser fluence. At $1.9 \mathrm{~J} \mathrm{~cm}^{-2}$, the $\mathrm{O}^{+}$ion shows a $10 \mathrm{eV}$ wide distribution centered at $30 \mathrm{eV}$, but this is not seen at lower fluence. The distribution for $\mathrm{O}^{-}$is relatively broad and lies in the $0-10 \mathrm{eV}$ region; it grows in strength with increasing fluence.

\section{Comparison of Langmuir probe and mass spectrometer TOA distributions}

When negatively biased the Langmuir probe measurement gives information about density and velocity of the positive ions in the plasma. From the $E_{k}$-resolved mass spectrometry measurement, the amount of the positive/negative ions with a specific mass-to-charge ratio is measured as a function of kinetic energy. It is of interest to see the extent to which the ion TOA recorded by the Langmuir probe can be reconciled with the ion energy distributions measured by the mass spectrometer. Since both experiments were conducted in vacuum at a fixed target-probe (detector) distance, the arrival time, $t$, of the ions is converted from its kinetic energy $\left(E_{k}\right)$ by: $t=\frac{d}{v}=d \sqrt{\frac{m}{2 E_{K}}}$. This was done by using the energy distribution $\left(d N / d E_{k}\right)$ for each positive ion to calculate the TOA signal $(d N / d t)$ due to that ion at the position $d=6 \mathrm{~cm}$ of the Langmuir probe, thus

$$
\frac{d N}{d t}=\frac{\left(2 E_{k}\right)^{\frac{3}{2}}}{m_{i}^{\frac{1}{2}} d} \times \frac{d N}{d E_{k}} .
$$

Figures $7(a)-7(e)$ show the TOA signals at $6 \mathrm{~cm}$, derived from the measured energy distributions, for the ions $\mathrm{O}^{+}$, $\mathrm{Ca}^{+}, \mathrm{Mn}^{+}$and $\mathrm{La}^{+}$and $\mathrm{LaO}^{+}$, respectively. Note that the y-coordinate scale is different in each plot. Fig. 7(f) shows the TOA distribution of $\mathrm{O}^{+}$with smaller abscissa scale as compared to Fig. 7(e). The strongest signals are due to $\mathrm{Ca}^{+}$and $\mathrm{Mn}^{+}$. Here, it is worth noting the close correspondence between the features seen in the period 14 to $20 \mu \mathrm{s}$ in the TOA distributions of $\mathrm{La}^{+}$and $\mathrm{LaO}^{+}$. The data clearly suggest that $\mathrm{LaO}^{+}$is found in the rear of the ablated plume, closer to the target, and the later feature in the $\mathrm{La}^{+}$distribution is likely derived from a dissociation of $\mathrm{LaO}^{+}$as it transits from the place of production to the aperture of the spectrometer. The later arrival time of $\mathrm{La}^{+}$ and $\mathrm{LaO}^{+}$can also be attributed to their larger atomic mass. Therefore, these species contribute more to the tail end of the TOA distributions. This can also be noted when converting the maximum of the TOA into a velocity. The heavy $\mathrm{LaO}^{+}$species travel at $\sim 3.2 \times 10^{3} \mathrm{~m} / \mathrm{s}$, whereas $\mathrm{v} \approx 1.4 \times 10^{4} \mathrm{~m} / \mathrm{s}$ for the lighter $\mathrm{Ca}^{+}$and $\mathrm{O}^{+}$is as fast as the electrons with $\mathrm{v} \approx 2 \times 10^{4} \mathrm{~m} / \mathrm{s}$ when ablated with a fluence of $1.9 \mathrm{~J} \mathrm{~cm}^{-2}$.

The overall derived positive ion TOA signal at $6 \mathrm{~cm}$ was obtained by adding together the individually derived ion TOA signals in Figs. 7(a)-7(e). The result is shown is Fig. 8(a) for the three fluence values of interest. For comparison, Figure 8 (b) shows the overall positive ion signal recorded by the Langmuir probe at $6 \mathrm{~cm}$ for the same fluence values. The quite good agreement between the net positive ion TOA distributions 
(a)

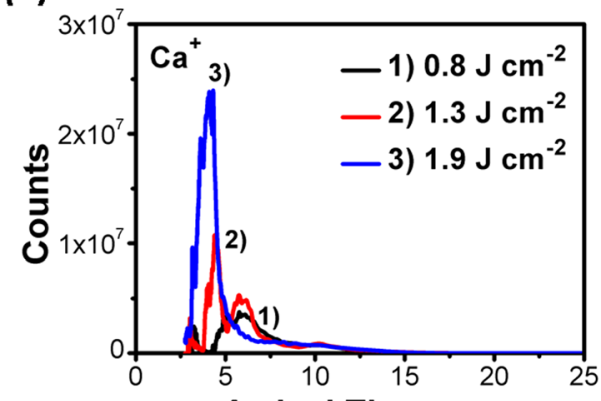

(c)

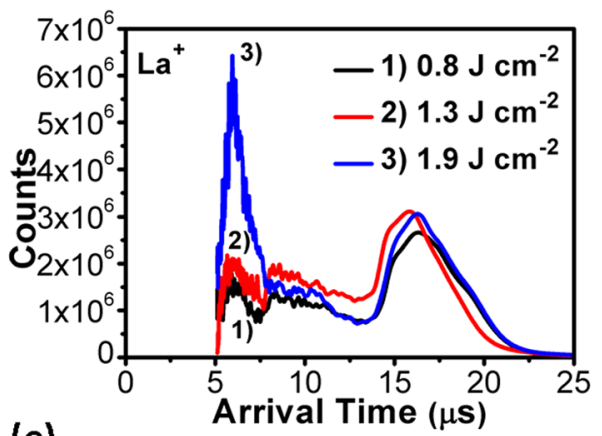

(e)

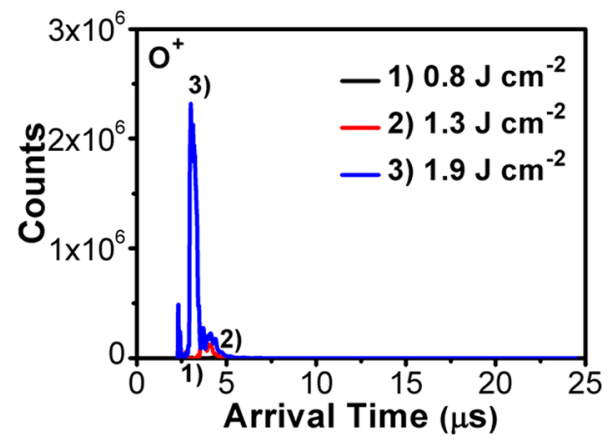

(b)

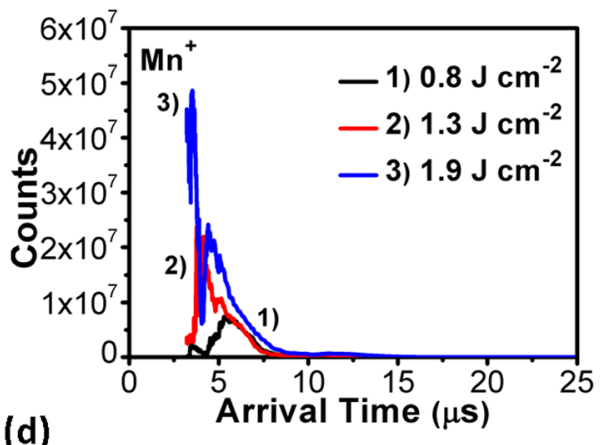

(d)

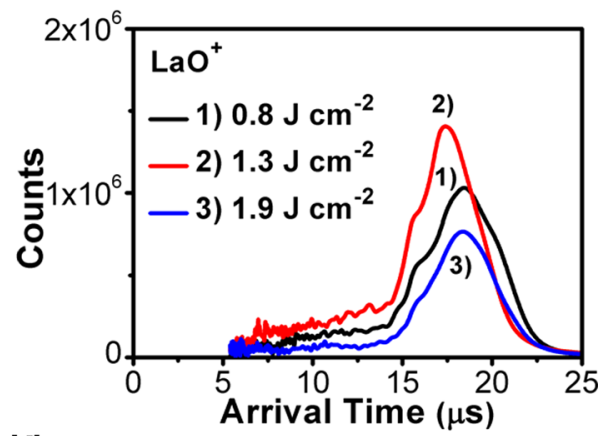

(f)

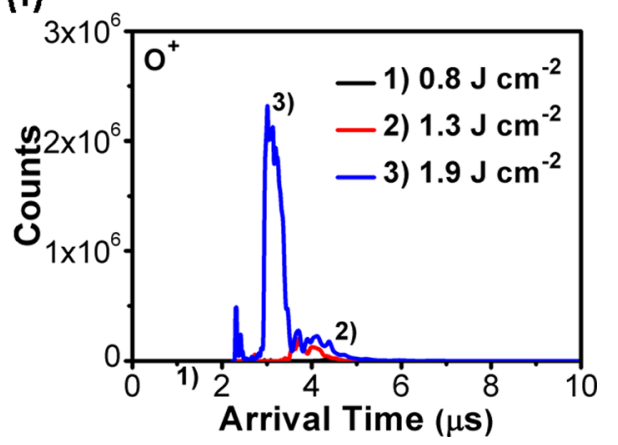

FIG. 7. (a)-(e) TOA distributions of $\mathrm{O}^{+}, \mathrm{Ca}^{+}, \mathrm{Mn}^{+}, \mathrm{La}^{+}$, and $\mathrm{LaO}^{+}$ions at $6 \mathrm{~cm}$ from the target as derived from the kinetic energy distributions in Fig. 5 plotted from 0 to $25 \mu \mathrm{s}$. (f) TOA distributions of $\mathrm{O}^{+}$from 0 to $10 \mu$ s. obtained by these two techniques gives confidence that they are providing a reliable diagnosis of the plasma plume formed by the ablation of LCMO. From Figures 8(a) and 8(b), it is clear that there are differences in the fine structures of the observed signal. For example, the broad hump from 14 to $20 \mu$ s appears in the TOA distribution from mass spectrometry but not for the Langmuir probe measurement. A possible reason could be a better discrimination of heavy ions by the mass spectrometer as compared to the Langmuir probe in this particular geometry because the ion signal is detected over a finite length of the ion probe.

The TOA distributions of $\mathrm{O}^{-}$at the probe position were also derived from the energy distributions, and they are plotted in Fig. 8(c). For all three fluences, the arrival times of $\mathrm{O}^{-}$ species at the probe position are significantly later than the arrival of the positive ions, indicating that the negative ions are found behind the plasma front, where the positive ions are mainly found. Figure 8(d) shows the Langmuir probe TOA signal for $10 \mathrm{~V}$ positive bias. By noting the relative magnitudes of the signals in Figs. 8(a) and 8(b) and then in Figs. 8(c) and 8(d), it can be concluded that the negative ions make a negligible contribution to the signal when the Langmuir probe is under positive bias; rather the signal is dominated by the much lighter electrons.

\section{Measurement of electron temperature and density}

The electron temperature and density in the ablation plume were measured at $6 \mathrm{~cm}$ for a range of time delays by plotting the logarithm of the electron current vs probe bias. The electron temperature, $T_{e}$, is given by the slope of the graph in the electron-retarding region. Figure 9(a) shows the $I V$ characteristic at $8 \mu \mathrm{s}$ at a fluence of $0.8 \mathrm{~J} / \mathrm{cm}^{2}$ (the temporal interval is $4 \mathrm{~ns}$ ), where the value of $T_{e}$ is $0.9 \mathrm{eV}$. The $I V$ characteristic can also be used to find the electron density by noting the current values at the knee in the curve, which corresponds to the plasma potential given by: $I_{e, s a t}=\frac{1}{4} e v_{e} A n_{e}$, where $v_{e}$ is the thermal velocity given by $\left(\frac{8 k T_{e}}{\pi m_{e}}\right)^{\frac{1}{2}}$. The value obtained from the $I V$ characteristic in Fig. 9(a) is $3.4 \times 10^{14} \mathrm{~m}^{-3}$. Figure 9 (b) shows the temporal dependence of electron temperature at the probe position, and Fig. 9(c) the temporal dependence of electron density.

To estimate the density of $\mathrm{O}^{-}$ions $\left(n_{-}\right)$, we define $\beta=\frac{n_{-}}{n_{+}}$, where $\left(n_{+}\right)$is the total positive ion density. Then, plasma charge neutrality implies that $n_{-}=\frac{\beta}{1-\beta} n_{e}$. If it is assumed that positive and negative ions, with the same velocity, are equally efficiently detected in the mass spectrometer, then the amplitudes of the signals in the derived TOA 
(a)

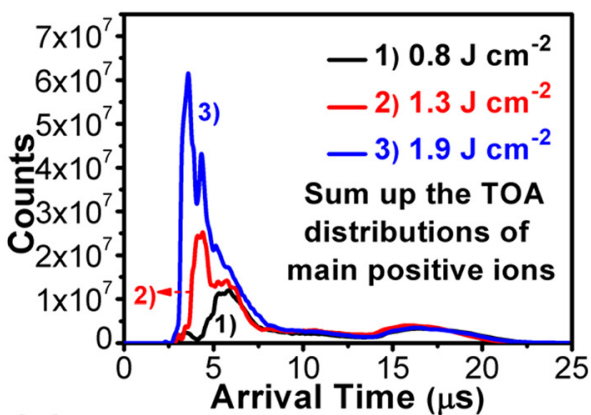

(b)

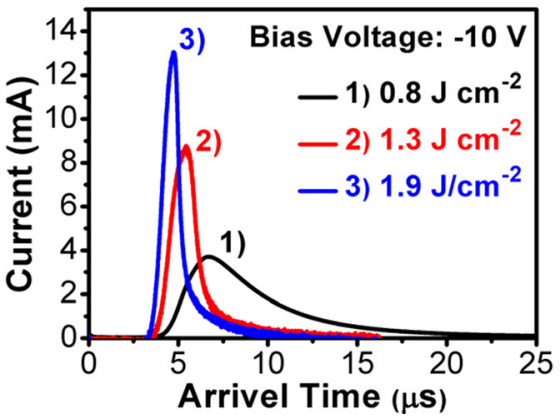

(c)

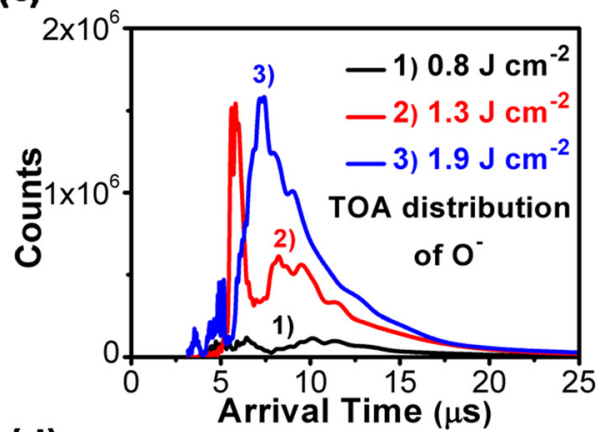

(d)

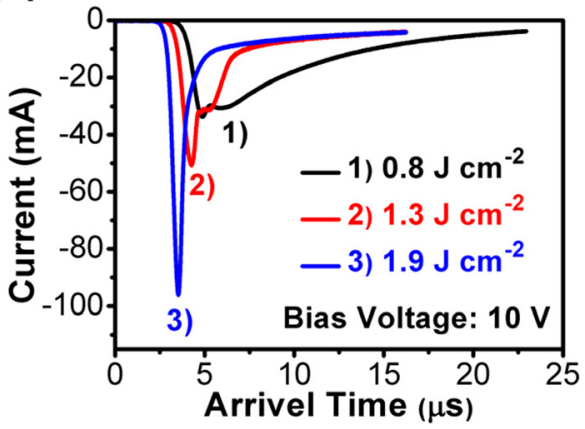

FIG. 8. (a) Net TOA distribution for all positive ions obtained by summing the distributions in Fig. 7. (b) Positive ion signals measured by Langmuir probe at $6 \mathrm{~cm}$ with a bias of $-10 \mathrm{~V}$; (c) TOA distributions of $\mathrm{O}^{-}$ions at $6 \mathrm{~cm}$ from the target as derived from the kinetic energy distributions in Fig. 5; (d) Electron signals measured by the Langmuir probe at $6 \mathrm{~cm}$ with a bias of $10 \mathrm{~V}$. distributions in Figs. 8(a) and 8(c) can be used to estimate the value of $\beta$. For example, at $10 \mu \mathrm{s} \beta=1 / 19$ : thus, since $\beta$ $\ll 1, n_{-}=\beta n_{e}$. Thus, using the measured electron density in Fig. 9(c), $n$ - can be estimated; the temporal variation of $n_{-}$is plotted in Fig. 9(d). It was noted earlier that the $\mathrm{O}^{-}$is the main negative ion species detected in the laser ablation plume. This is consistent with observations made on other types of oxygen plasmas, which have been shown to contain a significant fraction of $\mathrm{O}^{-}$. Since $\mathrm{O}_{2}$ is an electronegative gas, it is expected that $\mathrm{O}^{-}, \mathrm{O}_{2}{ }^{-}$, and $\mathrm{O}_{3}{ }^{-}$make a significant contribution to the charge balance in low temperature plasma. Negative oxygen ions are mainly formed by dissociative attachment and charge transfer, and destroyed by ionion neutralization and electron detachment. ${ }^{36}$ The negative ion densities can be calculated by detailed modelling of the reaction kinetics, or measured by photo-detachment. ${ }^{36}$ It has been reported that in a radio frequency (rf) excited 0.1 Torr oxygen plasma with an electron temperature of about $3 \mathrm{eV}$ the total negative ion density was 5 to 10 times the electron density and $n\left(\mathrm{O}_{-}\right)=4 \times 10^{15} \mathrm{~m}^{-3}$. Thus, it is to be expected that the laser ablation plume studied here will contain a significant fraction of $\mathrm{O}^{-}$ions, though, of course, a model of (a)

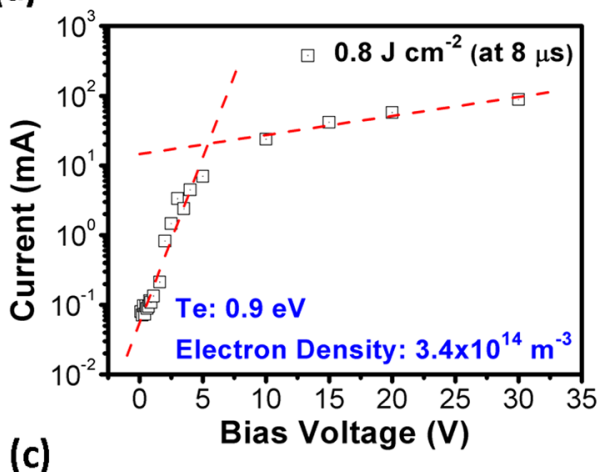

(c)

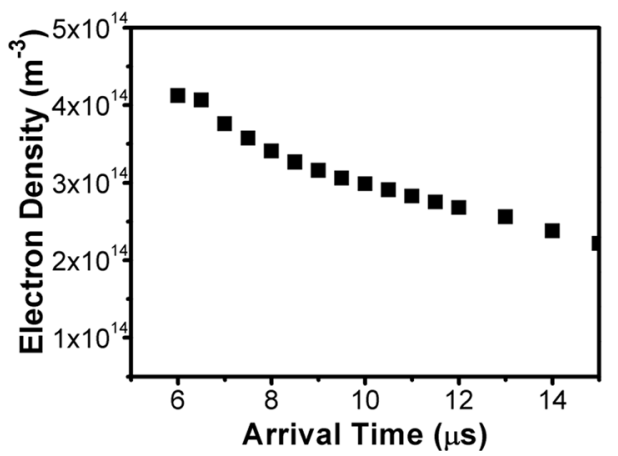

(b)

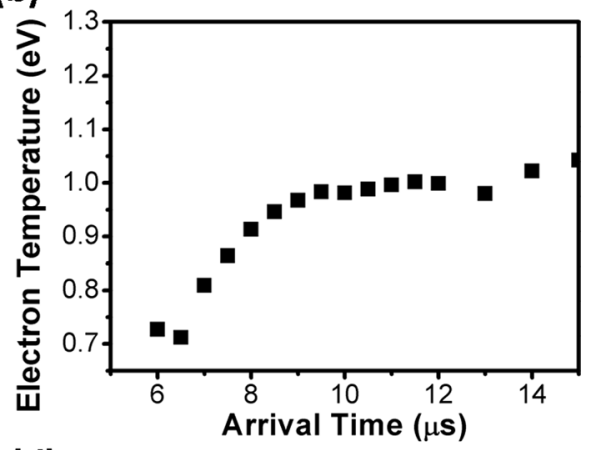

(d)

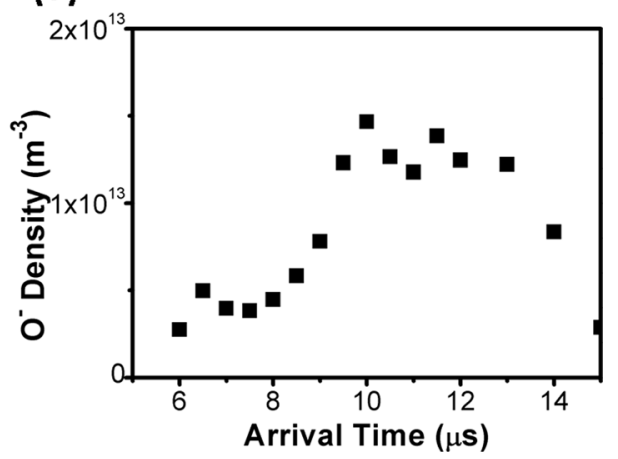

FIG. 9. Langmuir probe analysis, at $6 \mathrm{~cm}$ from the target, of the ablation plume formed at $0.8 \mathrm{~J} \mathrm{~cm}^{-2}$ : (a) $I V$ characteristic of the electron current signal detected by Langmuir probe at $8 \mu \mathrm{s}$; (b) temporal dependence of the electron temperature; (c) temporal dependence of the electron density; (d) temporal dependence of the estimated $\mathrm{O}^{-}$density. 
the reaction kinetics would need to include the metal atoms and ions, in addition to the oxygen species. It can also be noted that at the probe position the positive metal ions are found near the front of the plume expansion, while the $\mathrm{O}^{-}$ ions, which are detected somewhat later, are found behind the positive ion region.

\section{CONCLUSIONS}

We have examined the plasma formed by UV nanosecond laser ablation of LCMO in vacuum using both Langmuir probe analysis and energy-resolved mass spectrometry. The probe measurements show that both density and velocity of the positive ion species increase with laser fluence. Mass spectrometry shows that the main positive ion species are $\mathrm{Ca}^{+}$, $\mathrm{Mn}^{+}, \mathrm{La}^{+}$, and $\mathrm{LaO}^{+}$. The net TOA signal derived from the measured positive ion energy distributions is broadly consistent with the positive ion signal measured by the Langmuir probe. We also detected a significant number of $\mathrm{O}^{-}$ions, which arrive somewhat later than the main positive ion feature. The Langmuir probe was also used to measure the temporal variation of the electron density and temperature at $6 \mathrm{~cm}$ from the ablation target. In the period $(7-15 \mu \mathrm{s})$ when $\mathrm{O}^{-}$ions are found at this position, the plasma conditions $\left(T_{e}=0.9-1.0 \mathrm{eV}, n_{e}=4-2 \times 10^{14} \mathrm{~m}^{-3}\right.$ ) are consistent with the conditions required for significant negative oxygen ion formation, as revealed by studies on rf excited oxygen plasma.

\section{ACKNOWLEDGMENTS}

This work was partially supported by SNF (Project No. 200021-134577) and the Paul Scherrer Institute.

${ }^{1}$ D. H. Lowndes, D. B. Geohegan, A. A. Puretzky, D. P. Norton, and C. M. Rouleau, Science 273(5277), 898-903 (1996).

${ }^{2}$ P. R. Willmott and J. R. Huber, Rev. Mod. Phys. 72(1), 315-328 (2000).

${ }^{3}$ S. A. Chambers, Adv. Mater. 22(2), 219-248 (2010).

${ }^{4}$ B. Doggett and J. G. Lunney, J. Appl. Phys. 105(3), 033306 (2009).

${ }^{5}$ G. Baraldi, A. Perea, and C. N. Afonso, J. Appl. Phys. 109(4), 043302 (2011).

${ }^{6}$ I. Weaver, G. W. Martin, W. G. Graham, T. Morrow, and C. L. S. Lewis, Rev. Sci. Instrum. 70(3), 1801-1805 (1999).

${ }^{7}$ B. Doggett, C. Budtz-Joergensen, J. G. Lunney, P. Sheerin, and M. M. Turner, Appl. Surf. Sci. 247(1-4), 134-138 (2005).

${ }^{8}$ B. Toftmann, J. Schou, T. N. Hansen, and J. G. Lunney, Phys. Rev. Lett. 84(17), 3998-4001 (2000).

${ }^{9}$ B. Toftmann, J. Schou, and J. G. Lunney, Phys. Rev. B 67(10), 104101 (2003).
${ }^{10}$ G. Padmaja, A. V. R. Kumar, V. Vidyalal, P. Radhakrishnan, V. P. N. Nampoori, and C. P. G. Vallabhan, J. Phys. D: Appl. Phys. 22(10), 1558 (1989).

${ }^{11}$ C. Aruta, S. Amoruso, R. Bruzzese, X. Wang, D. Maccariello, F. M. Granozio, and U. S. di Uccio, Appl. Phys. Lett. 97(25), 252105 (2010).

${ }^{12}$ S. Amoruso, C. Aruta, R. Bruzzese, X. Wang, and U. S. di Uccio, Appl. Phys. Lett. 98(10), 101501 (2011).

${ }^{13}$ S. Amoruso, J. Schou, and J. G. Lunney, Europhys. Lett. 76(3), 436 (2006).

${ }^{14}$ A. Sambri, S. Amoruso, X. Wang, M. Radovic', F. Miletto Granozio, and R. Bruzzese, Appl. Phys. Lett. 91(15), 151501 (2007).

${ }^{15}$ S. Amoruso, R. Bruzzese, N. Spinelli, R. Velotta, M. Vitiello, and X. Wang, Phys. Rev. B 67(22), 224503 (2003).

${ }^{16}$ G. Epurescu, J. Siegel, J. Gonzalo, F. J. Gordillo-Vazquez, and C. N. Afonso, Appl. Phys. Lett. 87(21), 211501 (2005).

${ }^{17}$ S. Amoruso, C. Aruta, R. Bruzzese, D. Maccariello, L. Maritato, F. M. Granozio, P. Orgiani, U. Scotti di Uccio, and X. Wang, J. Appl. Phys. 108(4), 043302 (2010).

${ }^{18}$ O. Auciello, S. Athavale, O. E. Hankins, M. Sito, A. F. Schreiner, and N. Biunno, Appl. Phys. Lett. 53(1), 72-74 (1988).

${ }^{19}$ C. Girault, D. Damiani, C. Champeaux, P. Marchet, J. P. Mercurio, J. Aubreton, and A. Catherinot, Appl. Phys. Lett. 56(15), 1472-1474 (1990).

${ }^{20}$ C. Girault, D. Damiani, J. Aubreton, and A. Catherinot, Appl. Phys. Lett. 54(20), 2035-2037 (1989).

${ }^{21}$ M. Esposito, M. Bator, M. Dobeli, T. Lippert, C. W. Schneider, and A. Wokaun, Appl. Phys. Lett. 99(19), 191501 (2011).

${ }^{22}$ H. Dachraoui and W. Husinsky, Appl. Phys. Lett. 89(10), 104102 (2006).

${ }^{23}$ N. Chaoui, E. Millon, and J. F. Muller, Chem. Mater. 10(12), 3888-3894 (1998).

${ }^{24}$ T. Mathews, J. R. Sellar, B. C. Muddle, and P. Manoravi, Chem. Mater. 12 (4), 917-922 (2000).

${ }^{25}$ J. Chen, D. Stender, M. Bator, C. W. Schneider, T. Lippert, and A. Wokaun, Appl. Surf. Sci. 278, 317-320 (2013).

${ }^{26}$ T. Venkatesan, X. D. Wu, A. Inam, Y. Jeon, M. Croft, E. W. Chase, C. C. Chang, J. B. Wachtman, R. W. Odom, F. R. di Brozolo, and C. A. Magee, Appl. Phys. Lett. 53(15), 1431-1433 (1988).

${ }^{27}$ D. B. Geohegan and A. A. Puretzky, Appl. Surf. Sci. 96-98, 131-138 (1996).

${ }^{28}$ S. Amoruso, R. Bruzzese, R. Velotta, N. Spinelli, M. Vitiello, and X. Wang, Appl. Surf. Sci. 248(1-4), 45-49 (2005).

${ }^{29}$ B. Thestrup, B. Toftmann, J. Schou, B. Doggett, and J. G. Lunney, Appl. Surf. Sci. 208-209, 33 (2003).

${ }^{30}$ P. R. Willmott, R. Timm, and J. R. Huber, J. Appl. Phys. 82(5), 2082-2092 (1997).

${ }^{31}$ L. Torrisi, F. Caridi, D. Margarone, and A. Borrielli, Appl. Surf. Sci. 254(7), 2090-2095 (2008).

${ }^{32}$ I. A. Jon, J. G.-V. Francisco, and M. Roberto, Plasma Sources Sci. Technol. 21(1), 015016 (2012).

${ }^{33}$ D. Doria, A. Lorusso, F. Belloni, V. Nassisi, L. Torrisi, and S. Gammino, Laser Part. Beams 22(4), 461-467 (2004).

${ }^{34}$ X. Wang, S. Zhang, X. Cheng, E. Zhu, W. Hang, and B. Huang, Spectrochim. Acta, Part B 99, 101-114 (2014).

${ }^{35}$ See http://www.hidenanalytical.com/ for details about the EQS analytical system.

${ }^{36}$ E. Stoffels, W. W. Stoffels, D. Vender, M. Kando, G. M. W. Kroesen, and F. J. de Hoog, Phys. Rev. E 51(3), 2425-2435 (1995). 